\title{
Challenges and Opportunities for School-based Sexual and Reproductive Health Education: A Qualitative Study with Bangladeshi Islamic Leaders
}

\section{Mohammad Ali}

Uppsala Universitet Medicinska och farmaceutiska vetenskapsomradet Jonna Arousell

Uppsala Universitet Medicinska och farmaceutiska vetenskapsomradet

\section{Birgitta Essén}

Uppsala Universitet Medicinska och farmaceutiska vetenskapsomradet

William Ugarte ( $\nabla$ william.ugarte@kbh.uu.se )

Uppsala University https://orcid.org/0000-0003-4737-7705

Research article

Keywords: sexual and reproductive health education, adolescents, Islamic leaders, religious norms, Bangladesh

Posted Date: November 19th, 2020

DOl: https://doi.org/10.21203/rs.3.rs-76606/v1

License: (9) This work is licensed under a Creative Commons Attribution 4.0 International License. Read Full License 


\section{Abstract}

\section{Background}

It has been argued that Islamic leaders' views are of utmost importance to designing a comprehensive sexual education (CSE) curriculum. Therefore, this study explored how Islamic leaders in Bangladesh present, argue for and against, and negotiate views on sexual and reproductive health (SRH) education for adolescents.

\section{Methods}

Semi-structured interviews were conducted with seven Imams using thematic analysis. The study was conducted in urban and rural areas, specifically the capital, Dhaka, as well as several rural villages in the Cumilla district.

\section{Results}

We found three main themes 1) appropriate topics for SRH education, 2) appropriate methods for SRH education, and 3) conservative versus progressive views.

\section{Conclusion}

We conclude that Islamic leaders seemed willing to try finding ways to support more comprehensive and liberal SRH education if they would be encouraged by reflective and inclusive dialogue. This study presents an empirically grounded opportunity for policy makers to consider the future role for religious leaders in the provision of SRH in Bangladesh.

\section{Background}

Public health literature has shown that Bangladeshi adolescents aged 11-19 have considerable knowledge gaps with regard to topics like menstruation, the transmission of sexually transmitted infections (STIs), human immunodeficiency virus (HIV) and acquired immune deficiency syndrome (AIDS). Moreover, the rate of adolescent marriage and pregnancy is high in Bangladesh [1]. One study found that only $42 \%$ of married adolescents used contraceptives, and $50 \%$ of married women in the south-western region of Bangladesh had become pregnant before the age of 15 [2]. Notably, Bangladeshi adolescents expressed a strong interest in learning about many aspects of sexuality [3]. The majority of adolescents use various informal sources to get information, such as peers, media (print and electronic), and the Internet, but most of the information is neither useful nor reliable $[4,5]$. Importantly, the health literature offers evidence that comprehensive sexuality education (CSE) is effective in empowering young people to make informed decisions about their own sexual and reproductive health (SRH) i.e.

contraceptives, marriage, and child planning, and decreasing sexual activity and risk-taking behaviour [6]. However, Muslin youths and particularly Bangladeshi adolescents face severe difficulties to access both services and education related to SRH or CSE $[4,5,7]$. 
Although, thirty-two SRH programs have been implemented with the support of the Government of Bangladesh, including local and international organizations working with $\mathrm{SRH}$, all of these programs have some severe limitations. For example, targeting rural and not urban areas and being focused much on girls than boys. Only 16 programs have focused exclusively on adolescents aged 10-19. Like in other South Asia countries, the biggest limitation of these programs is that due to social and cultural unacceptability young unmarried people are not allowed to seek and receive services related to pregnancy, menstrual regulation, family planning methods, and post-abortion care [5, 8]. Consequently, all NGOs in the country avoid using the terms sex and sexuality in their official names, demonstrating how these topics are sensitive to discuss due to cultural norms [9].

Nevertheless, the Bangladesh National Strategy for Adolescent Health has sought to include, integrate and strengthen age-appropriate CSE for adolescents in Bangladesh [1]. Thus in 2013, the Bangladesh Educational Board briefly introduced some SRH topics in the three textbooks from grade six to ten. SRH topics included puberty, menstruation, the right age for marriage and pregnancy, problems regarding early fertility, the prevention and protection of STIs, HIV, and AIDS. The National Curriculum Coordination Community had ensured that the textbooks contained culturally appropriate information before distributing them to students. However, parents, teachers, and even senior officials of the Ministry of Education argued that the information in the chapter on puberty and reproductive health in the textbooks were not culturally appropriate because they might tempt adolescents to engage in premarital sex. As a result, the Ministry of Education and the Bangladesh Madrasha Education Board edited and excluded the SRH content [10].

Several studies have emphasized that parents, teachers, community and religious leaders are key stakeholders in the development of health and rights-based CSE in Bangladesh $[8,10]$. Particularly, parents have expressed positive attitudes towards a liberal SRH education such as family planning, ejaculation, and puberty. However, a study found that parents felt uncomfortable discussing SRH with their children and perceived sex education as self and automatic learning [4]. In similarity to parents, teachers also reported feeling uncomfortable teaching the SRH information and omitted sensitive topics in the classroom $[9,10]$. More specifically, teachers feared being criticised and excluded from their communities [5].

Although, in many Islamic countries, religious leaders play vital roles in approving or disapproving many aspects of SRH policies $[12,13,14]$. The discrepancies between the Muslin adolescents' views and needs on sexuality and the role of Imams using an Islamic doctrine may affect the development and delivery of sex of CSE programs [7]. While recent studies from Muslim majority countries such as Malaysia [15] and Jordan [16] have explored religious leaders' various approaches to SRH right related questions and education, to this date, equivalent studies are lacking in a Bangladeshi context. This present study, therefore, explored Bangladeshi Islamic leaders' views on how they present, argue for and against, and negotiate views on, SRH education for adolescents. Accordingly, the aim of this paper was to explore what approach to SRH education they would consider acceptable. 


\section{Material And Methods}

\section{Study design, setting, and participants}

A qualitative study was conducted to explore the views of Bangladeshi Islamic leaders concerning school-based SRH education. The study was conducted in urban and rural areas, specifically the capital, Dhaka, as well as several rural villages in the Cumilla district. Purposeful sampling was used to choose religious leaders who work as Imams, i.e., Muslims who serve as prayer leaders and spiritual advisors to the congregation of a mosque. There is no specific education required to be Imams. Rather, in Bangladesh, they study in Madrasha, which is an Islamic religious school established in the year 1971. Madrasha system in Bangladesh is divided into two sectors: 1) Alia Madrasha 2) Quami Madrasha. The Bangladesh Madrasha Board regulates Alia Madrasha, but Quami Madrasha is an independent and unregistered, which are not regulated by the Bangladesh Madrasha Board. Therefore, finding accurate information on Quami madrashas is very challenging. The Alia Madrasha provides modern general education and have similar core courses as general schools, but emphasize on religious studies from one to master's degree. Seven participants (three urban and four rural) were included. Six participants had a Kame/ degree in Islamic studies (equivalent to a Master's degree) and worked as both as imam and teachers. One participant was a Mawlana graduate (scholarly studies from Quami madrasha) and worked as an imam in a mosque. The youngest participant was aged 35 years and the oldest was aged 58 years.

\section{Data collection}

The first author, in the Bangla language, conducted seven semi-structured face-to-face interviews during the period January-March 2018 the informants' socio-demographic data (age, education and work experience) was recorded at the beginning of the interview. The interview guide was adapted from key interviews with teachers and principals designed to make inquiries about their personal views, opinions, and perceptions about SRH education in the Pacific Islands [17]. Additional questions were added from studies among Muslim adolescents [3, 7] and parents [11]. (See additional file 1). The questions were used with discretion to explore the religious leaders' views toward the education of adolescents related to puberty, marriage, pregnancy, contraception, sexuality and safe sex practice, STI, and HIV and AIDS. Interviews lasted 30-45 minutes and were audio-recorded. All interviews were transcribed verbatim in Bangla and were crosschecked by a local expert.

\section{Data Analysis}

Thematic analysis was used to identify overarching themes in accordance with the aim of the study [18]. Firstly, the data were read several times. Secondly, open codes were developed by identifying sentences or words used by the participants that would explain what aspects of SRH education they would consider acceptable and not acceptable. Thirdly, all relevant codes were gathered to each potential theme.

Fourthly, the potential themes were carefully compared with the coded extracts and the entire data set. The final themes were made based on ideas of the aims of the study. The first two steps in the analysis 
process were conducted in Bangla and thereafter in English. All authors contributed to the data analysis process, which was important to control for any potential for interpretive bias arising from the first author's role as sole interviewer.

\section{Results}

\section{Appropriate topics for SRH education}

The informants asserted that sex and reproduction are special gifts from Allah (God), and important elements of human life. The informants did not refer to SRH education for adolescents as being forbidden; rather they suggested that SRH education must be taught in accordance with Sharia (i.e. Islamic religious laws and principles). The first priority for the religious leaders was the promotion of abstinence and morality-based sex education. One informant's statement provides a good illustration of what abstinence-based sex education for young people could be like:

"It is natural that young people experience emotions, like a boy likes to love a girl and a girl likes to love a boy although it is not permitted in Islam. So we [society] must teach those [young people] that they should not get involved in illegal activities [love, romantic relationship, and premarital sex]" (Informant 1, 48 years old)

During the interviews, several informants described premarital sex, love, and romantic relationships as "illegal activities". According to the informants, a boy or girl experiences physical changes during "jowban kal", meaning the adolescent period, and at the same, a girl or boy experiences "jowno akangkha", meaning sexual desires. Some informants argued that there are some adolescents who can control their sexual desires (not involving love and romantic relationships), whereas others cannot. The adolescents who can control their sexual desires were by informants described as "successive adolescents". Informants argued that it is their obligation to prevent youth, who cannot control their sexual desires, from acting upon them. Several informants presented social media such as mobiles and Facebook as causes for stimulating adolescents' sexual desires. One informant described:

"But, nowadays boys and girls are involving themselves in Prem and Valobasha [romantic relationship and love] through their mobile phones in front of their parents. A few days ago, I saw a girl using her phone and later I had noticed that she was talking with a boy. They were involved in such activities [love and romantic relationship] through the use of their phones." (Informant 6, 56 years old)

In addition, informants constructed education related to menstruation as being appropriate and necessary. They referred to sections in the Hadith (Prophet Muhammad's messages) concerning haydi (menstruation), and the importance of cleanliness in Islam. Due to the requirement for ritual purification, several informants argued that girls must know how to purify themselves properly. Moreover, according to many informants, boys experience "soppnodosh" meaning wet dream was viewed as a natural phenomenon during adolescents' period. Therefore, they would like boys to learn how to clean their body 
once boys experience wet dream. On the other hand, some informants stated that boys experience wet dream when they think too much opposite gender.

"Generally, I know that boys experience soppnodos. Since I am a male, therefore I know better about boys' matters [soppnodos]. A boy experience soppnodos when he starts reading grade 7 or 8 . Boys only experience it [soppnodos] when they [boys] imagine about girls. Everyone experience it. Some more and some less." (Informant 2, 35 years old)

The informants were open to discussing this topic with students, but they claimed that their ultimate objective was to teach girls that menstrual blood is impure. Most informants argued that Islam does not prohibit teaching adolescents about HIV and AIDS. The informants expressed great concern about the increase of HIV and AIDS in Bangladesh, and presented SRH education as a means to help adolescents become aware of HIV and AIDS and prevent its spread.

\section{Appropriate methods for SRH education}

Informants described the teaching method for their suggested SRH education; however, diverse opinions were expressed. Some informants argued that SRH education should be introduced in the upper years of secondary school, for example, in grade nine. One informant stated:

"Sometimes, boyshondhi shikha [Bangla term for SRH education] is taught in grade 6, but a boy or girl is only 11 years old when he or she reads in grade 6. I am saying from my personal experience that students [grade 6] not only feel shy to read about boyshondhi shikha but they also learn about gopon [secret] things" (Informant 6, 56 years old)

The quote illustrates how some informants were eager to claim that young adolescents should not learn about SRH issues since it is considered very secret for young adolescents. On the other hand, one informant alleged that young adolescents should be taught about SRH issues. He describes "this issue [SRH] as being important for girls because they experience hyes [menstruation] at an early age. There are many [girls] who often experience hyes at very early ages, but they [girls] are not aware of this [menstruation]. They [girls] should be taught about this [menstruation]" (Informant 7, 60 years old)

Moreover, almost all informants argued that SRH education must not be delivered in mixed-gender classes because co-educational teaching would increase the risk of intimacy between boys and girls, which Sharia forbids. The informants presented modesty as an important value in their religion. Therefore, they argued that sexually liberal discussions about SRH would risk reducing adolescents' shyness and that this, in turn, would challenge the maintenance of modesty.

"(laugh...) there is shyness which comes automatically. There is a sentence in Hadith, if a person does not have shyness that means he/she does not have anything [...] we [Muslims] have shyness and that is why we cannot discuss everything openly (laugh)." (Informant 5, 57 years old) 
The same informant argued that society would not accept a liberal discussion related to SRH information. He replied:

"People will take [SRH issues] negatively. No one will take [SRH] as a positive, particularly, in Bangladesh since the majority of people are Muslims [...] many people will not accept [SRH] if it is made too open [transparent and sexually liberal discussion]" (Informant 5, 57 years old)

Informants suggested ways for teaching SRH without violating modesty. Teachers could think about using appropriate terms, such as "chest increase" (breast formation), "hayes" (menstruation), and "night pressure" (wet dream). However, other informants displayed some struggles to think of teaching methods that could be applied without violating modesty. One informant said that they should find a technique for this teaching method as if he was not sure what it might be.

\section{Conservative versus progressive views}

\section{Conservative views}

All of the informants represented Islam as an open religion that does not encourage people to keep anything secret. Informants argued that awareness is key in their religion. Informants referred to their prophet Muhammad who taught people about different aspects of SRH. One informant gave an example that once there was a woman who came to Prophet Muhammad to know about menstruation. The prophet gave her information about menstruation with the help of his wife. However, it appeared in the interviews that some informants did not want to discuss some topics related to SRH. During a discussion about family planning for unmarried adolescents, one informant stated:

"I am telling you that since sexual relationships outside marriage are not permitted in Sharia, I do not feel good being asked about it [family planning]" (Informant 4, 48 years old)

Similarly, another informant avoided discussing child marriage, but later in discussion on the child marriage law in Bangladesh, he posited:

"Sharia does not consider people's health rather [Sharia] considers how a person can be saved from the fire of the hell. If a girl is involved in a sinful act [premarital sex] before she reaches 18 [.....] in this particular case, she should be married before 18." (Informant 3, 42 years old)

The study's findings showed that contraceptives and family planning methods often were presented as controversial issues among the informants in the study. The informants opposed the notion of teaching about condoms and other family planning methods for unmarried adolescents, constructing it as unacceptable and harmful because it might lead to an increase in premarital sex. There was some disagreement about contraception for married couples. Several of the religious leaders presented contraceptives and family planning methods as being unlawful in Islam. Others argue that contraceptives and family planning methods are permitted for married couples in particular situations, for example, if a women's health is at risk due to complicated pregnancy. Some informants also expressed doubt about 
the effectiveness and benefit of contraceptives. One participant said that he had read that condoms, contraceptive pills, and contraceptive injections have side effects and that they are not completely effective. Moreover, he presented condom as a contraceptive that might cause infertility and which therefore should be avoided:

"I read about the side effects of condom use in a family planning book where I came to understand that condom use causes problems in joraiyo [uterus] such as ulcers. At some point, condom use can cause bondha [infertility]" (Informant 4, 48 years old)

\section{Progressive views}

Although the informants were from rural and urban areas, this study found no major differences in the way they responded, with a variety of viewpoints in both settings. Most importantly, despite several informants expressing a restrictive view of SRH education, others favoured interpretations of Sharia that were more progressive. This latter group argued that Islam pays great attention to peoples' health, and does not want people to be hurt. According to this perspective, Sharia could be used as a helpful guide for promoting SRH education, which could have a positive effect on adolescents' general SRH in the long run. For instance, although many of the Islamic leaders were strongly against education related to family planning, as stated above, one suggested that family planning information could be introduced in the upper years of secondary school:

"Family planning can be taught for boys and girls above the age of 18, since 18 years is the legal age for marriage. As boys and girls are not allowed to get married before 18, family planning education should not be taught before 18. This is my personal opinion." (Informant 6, 56 years old)

Because this was a unique view, the informant was asked why his opinion differed from other participants. He replied that most Bangladeshi adolescents get married at the age of 18 and that family planning information might help young couples to use contraceptives more effectively. One other informant also presented family planning as a topic to be taught based on Sharia, but he was not sure about the permissible content, that he felt that he lacked sufficient knowledge of such a broad issue. Moreover, some informants argued with certainty that Sharia neither permits nor prohibits child marriage. Yet, child marriage was represented as a practice that might cause both physical and psychological health problems for girls:

"Child marriage is not prohibited in Sharia. Our Prophet's wives were married at a young age, but human life has changed a lot over time. Sharia justifies the circumstances that are beneficial for human beings. Sharia has not determined everything from the old-time." (Informant 7, 60 years old)

\section{Discussion}

This study sought to explore Bangladeshi Islamic leaders' views on SRH education. We found that the Islamic leaders presented it as their obligation to provide guidance on $\mathrm{SRH}$ issues according to their religious norms. This is consistent with other studies of Islamic leaders with specific reference to abortion 
advice [19] and birth spacing policies [13]. However, their attitudes toward SRH education seemed to be mainly at a moral level than right and health based. This attitude might have influenced the religious leaders' selection of SRH topics to be taught in this education, which was discussed in the section that follows.

\section{Religious leaders' preference for SRH topics including teaching method}

Our findings showed that premarital sexual activity has been a great concern for the religious leaders in this study. Most leaders presented premarital sex as a major sin, according to their religious interpretations. Therefore, abstinence-based sex education was presented as the most effective, appropriate, and popular intervention among the informants. Notably, the sex education that the religious leaders discussed in this paper is practically identical to the vast majority of sex-education lessons taught in American schools [19]. At the same time, other studies have shown that abstinence-based sex education has no effect on adolescent sexual behaviour [21]. However, it is important to remember that abstinence-based or CSE should be prioritized based on adolescents' SRH figures i.e. marriage, pregnancy, rate of contraceptives use and the health care facilities of the country. In the Bangladeshi context, adolescents' SRH health is vulnerable, particularly because the rate of child marriage and pregnancy is high, that the rate of contraceptive use is low, and that they have limited ability regarding $\mathrm{SRH}$ decisions that they want. Moreover, unmarried youth have severe difficulties in accessing SRH services in both government and NGO clinics [8], making it difficult to generally present abstinence-based sex education as the best alternative with regard to Bangladeshi youths' sexual and reproductive health.

\section{Interpretation of Sharia plays a big role}

The interpretations of Sharia among the informants, in what regards SRH topics, were varied, different, and contradictory. For example, there were informants who used family planning as an example of something against their religion's laws. Other, however, presented family planning as being permitted for married couples. This result resonates with a previous study on Somalian religious leaders' views on birth spacing [13], which also found that all informants were against the use of condoms except one. Another study stated that Islam is a diverse religion and its interpretation varies from country to country, within countries, and between Sunni and Shia Muslims and other divisions [22]. In fact, one informant posited that "Sharia has not determined everything from old-time" meaning Sharia could be reinterpreted. Notably, the Islamic community has a long history of professional legal scholars and jurists, who are trained to make decisions where interpretations are necessary [22]. Importantly, some informants provided liberal interpretations of Sharia or liberal recommendations on a few SRH topics meaning intentionally helping health outcomes. For instance, while they acknowledged that, their Prophet's wives married at young ages and reasoned that child marriage is not prohibited in their religion; several informants were against child marriage offering objective medical explanations. Similarly, Arousell et al. identified Muslims religious informants provided liberal recommendations on abortion [19]. Moreover, while many religious leaders in our study presented family planning and contraceptive education as illegitimate; one informant felt that 
family planning information could be introduced in the upper years of secondary school. Moreover, he provided health-based justification for this. One of the possible reasons for his liberal opinion could be that this informant had attended several seminars related to youth health arranged by governmental and non-governmental organizations. This is consistent with a study that has shown that that religious leaders' traditional views may become more liberal and permissive if they are exposed to health-based training [16]. This suggests that it could be possible to facilitate a more dialogue-based approach with regard to religious leaders' roles in SRH education.

\section{Implications for SRH policies in Bangladesh}

The overall findings from this study show that there are both challenges and opportunities at play if religious leaders are involved in SRH education, and if their opinions are given weight in national SRH programming. One challenge is that both the religious leaders interviewed in this study as well as the government of Bangladesh, including national and international non-government organizations, want adolescents to be taught about $\mathrm{SRH}$, but in quite different ways and for different purposes. While the religious leaders want adolescents to be taught a few SRH topics based on religious norms, the government of Bangladesh has identified the need for comprehensive SRH education based on best available evidence from existing research. In addition to national policy, the government of Bangladesh has committed to the United Nations' Sustainable Developmental Goals (SDGs). Adolescent health has been prioritized in the SDGs, particularly goal 3, which aims to ensure universal access to SRH services and education [23]. Consequently, of signing on to the SDGs, in 2016 the Bangladesh National Strategy for Adolescent Health was modified to include integrating and strengthening age-appropriate comprehensive sexuality education. The strategy is based on promoting adolescent rights to attain the highest standards of health, irrespective of gender, age, class, caste, ethnicity, religion, disability, civil status, and sexual orientation: a perspective that might not be supported by religious leaders in the country. The religious leaders' approach to SRH education would not always contribute to the national and global goals for health and health-related education. The challenge that must be further discussed among policy makers is, in other words, how to proactively combine religious ideas with evidence-based knowledge when designing SRH programs.

The second challenge is that the SRH information suggested by the Islamic leaders would likely not engage adolescents in the learning process and contribute to fulfil their SRH demand in an effective way. It has been argued that Bangladeshi adolescents' have a demand for more information related to SRH. For example, students in the secondary public school expressed strong curiosity to know about sexuality issues and viewed the current textbooks with SRH information as insufficient and normative. $[3,10]$. In addition, the relationship between Muslin adolescents and religious leaders' views on sexuality is conflictive and may affect the success of CSE programs [7]. Consequently, many adolescents appear to look for SRH information through other sources, such as from the media, internet, and peers $[8,10]$. Moreover, Madrasha students might face severe difficulties to access a more liberal approach of SRH. There is evidence that Bangladesh Madrasah Education Board did not distribute the 2013 textbooks with $\mathrm{SRH}$ information until the Madrasah authorities had edited and excluded the SRH content [10]. Therefore, 
we suggested that policy makers should raise this challenge while they enter into dialogue with religious leaders and what role they should play.

Nevertheless, the study also shows that there might exist good opportunities with regard to including religious leaders' in health-promoting activities. The study shows, for instance, that the religious leaders have more than one, single opinion about Islam in relation to SRH education. Some delivered quite conservative views, whereas others held opinions that could be interpreted as being more progressive. This implies that there are opportunities for policy makers to explore areas of compromise and shared values regarding SRH education for young people in Bangladesh today. The practice of abortion is an illustrative example. Muslim religious leaders played a key role in reforming the abortion law by giving more attention to social and medical reasons for abortion. Consequently, many Muslim countries now permit abortion in case of rape, foetal impairment, and in the case where the mother's life is danger [22]. There are a few religious leaders in the present study that supported some kind of SRH education on medical grounds (not religious grounds). Therefore, it is possible that religious experts will find a way to support more comprehensive sexuality education if they are encouraged by sensitive, open, and inclusive dialogue.

\section{Methodological considerations}

The qualitative method is largely considered as an appropriate method for this study. Evidently, the qualitative method provides researcher a deeper understanding of individual experience, opinion, belief and behavior in a particular phenomenon [24]. Notably, the purpose of the qualitative study is not generating statistically generalizable findings; rather it helps researchers to understand larger social phenomena derive from informants' inner experience including specifics examples of their everyday life. In other word: the findings of this paper are not representative to all religious leaders in Bangladesh. In terms of ideology, there is a diverse group of Islamic leaders, imam, and scholars in Bangladesh. This paper covered the first two segments. Finally, SRH education is very political in Bangladesh, therefore, it cannot conclude based on the findings from the two types of imam. In our view, taking more sample from diverse groups on this issues are of utmost feasible and important.

\section{Conclusion}

This study identified several challenges arising from traditional Muslim leaders' views of SRH education. While some of the leaders held conservative views regarding SRH education, others have opinions that are more progressive. This range of views creates an opportunity for policy makers to explore religious approaches that could harmonize with Bangladesh's national plan for SRH education for young people and similar contexts.

\section{List Of Abbreviations}

AIDS: Acquired Immunodeficiency Syndrome 
CSE: Comprehensive Sexual Education

HIV: Human Immunodeficiency Syndrome

NGO: Non-governmental Organization

SDGs: Sustainable Developmental Goals

SRH: Sexual and Reproductive Health

STI: Sexually Transmitted Infections

\section{Declarations}

\section{Ethical approval and consent to participate}

The Sir Salimullah Medical College Ethical Review Board approved this study. Informants received an information sheet in advance with detailed information about the study and their participation. The researcher informed the informants about the purpose of the study and their right to withdraw at any time. Informants were also informed that they could decline answering any questions and that all responses would be confidential. All participants provided written informed consent in both English and Bangla (See additional file 2 and 3).

\section{Consent for publication}

Not applicable

\section{Competing Interest}

The authors declare that they have no conflict of interest. The authors alone are responsible for the content and writing of the paper.

\section{Funding}

The Swedish Institute supported this study through a scholarship for the first author.

\section{Authors' contributions}

MA and BE contributed to the study conception and design. MA performed material preparation and data collection. All authors contributed to the study analysis. MA wrote the first draft of the manuscript. All 
authors commented on previous versions of the manuscript. All authors read and approved the final manuscript.

\section{Acknowledgments}

We would like to thank all the informants in this study for their time and information. We would like to thank Alex Berland, Senior Adviser for Health Sciences at the International University of Business Agriculture and Technology in Dhaka Bangladesh, for the proofreading. We also would like to thank Dr Mahibun Nahar, assistant professor, Department of Community Medicine of Sir Salimullah Medical College, Dhaka for reviewing transcribes.

\section{References}

1. Bangladesh National Strategy for Adolescent Health (BNSAH). MCH Services Unit Directorate General of Family Planning Ministry of Health and Family Welfare. 2016. http://coastbd.net/wpcontent/uploads/2017/07/National-Strategy-for-Adolescent-Health-2017-2030-Final-Full-Book-21-0617.pdf. Accessed 15 Nov 2019.

2. Amin S, Ainul S, Akter F, Alam MM, Hossain M, Ahmed J, et al. From evidence to action: results from the 2013 baseline survey for the BALIKA project. 2014. https://knowledgecommons.popcouncil.org/departments_sbsr-pgy/699/. Accessed 11 September 2019.

3. van Reeuwijk M, Nahar P. The importance of a positive approach to sexuality in sexual health programmes for unmarried adolescents in Bangladesh. Reprod Health Matters. 2013;21(41):69-77.

4. Khan TH, Raby R. From missing to misdirected: young men's experiences of sex education in Bangladesh. Sex Education. 2019; doi:1080/14681811.2019.1703177

5. Khan SA, Alam F, Rommes E, Rashid SF. Experiencing shame: An affective reading of the sexual and reproductive health and rights classroom in Bangladesh. Sex Education. 2020; doi:1080/14681811.2019.1707651

6. UN Women, and UNICEF. International technical guidance on sexuality education: an evidenceinformed approach. UNESCO Publishing. Available at: https://www.unwomen.org/en/digitallibrary/publications/2018/1/international-technical-guidance-on-sexuality-education. Accessed 14 October 2019.

7. Smerecnik C, Schaalma H, Gerjo K, Meijer S, Poelman J. An exploratory study of Muslim adolescents' views on sexuality: Implications for sex education and prevention. BMC Public Health. 2010;10, 533.

8. Ainul S, Bajracharya A, Reichenbach L. Adolescents in Bangladesh: Programmatic Approaches to Sexual and Reproductive Health Education and Services. Situation Analysis Brief. Dhaka, Bangladesh: Population Council, Evidence Project. 2016. https://www.popcouncil.org/uploads/pdfs/2016RH_AdolescentsBangladesh_SAbrief.pdf. Accessed 05 November 2019. 
9. Roodsaz R. Probing the politics of comprehensive sexuality education: "Universality" versus "Cultural Sensitivity": a Dutch-Bangladeshi collaboration on adolescent sexuality education. Sex Education. 2018; doi:1080/14681811.2017.1403894

10. Nazme S. Religious extremism and comprehensive sexual and reproductive health and rights in secondary and high secondary education in Bangladesh: national report, Bangladesh: building new constituencies for women's sexual and reproductive health and rights (SRHR): interlinkages between religion and SRHR. Naripokkho; Asian-Pacific Resource and Research Centre for Women. 2016. Accessed 03 September 2019.

11. Rob U, Ghafur T, Bhuiya I, Talukder N. Reproductive and sexual health education for adolescents in Bangladesh: parents' view and opinion. Int Q Community Health Educ. 2005;25(4):351-365.

12. Adedini SA, Babalola S, Ibeawuchi C, Omotoso O, Akiode A, Odeku M. Role of Religious Leaders in Promoting Contraceptive Use in Nigeria: Evidence From the Nigerian Urban Reproductive Health Initiative. Glob Health Sci Pract. 2018;6(3):500-514.

13. Egeh AA, Dugsieh O, Erlandsson K, Osman F. The views of Somali religious leaders on birth spacing - A qualitative study. Sexual \& Reproductive Healthcare. 2019; 20, 27-31.

14. Staski M. Enhancing Sexual and Reproductive Health and Well Being of Young People: Building Common Ground between the United Nations and Faith-Based Development Partners. 2012. UNFPA, New York. https://www.unfpa.org/publications/enhancing-sexual-and-reproductive-health-and-wellbeing-young-people. Accessed 25 October 2019.

15. Makol-Abdul PR, Nurullah AS, Imam SS, Rahman SA. Parents' attitudes towards inclusion of sexuality education in Malaysian schools. International Journal of Parents. 2010; 3, 42-56.

16. Underwood C, Kamhawi S, Nofal A. Religious leaders gain ground in the Jordanian family planning movement. International Journal of Gynecology \& Obstetrics. 2013; 123 Suppl 1, e33-e37.

17. Attitudinal survey report on the delivery of HIV and sexual reproductive health education in school settings in Nauru, Niue, Palau and Samoa. 2015. UNESCO Publishing. Available at: https://unesdoc.unesco.org/ark:/48223/pf0000232550. Accessed 04 January 2018.

18. Vaismoradi M, Turunen H, Bondas T. Content analysis and thematic analysis: Implications for conducting a qualitative descriptive study: Qualitative descriptive study. Nursing \& Health Sciences. 2013; 15(3), 398-405.

19. Arousell J, Carlbom A, Johnsdotter S, Essén B. Does Religious Counselling on Abortion Comply with Sweden's 'Women-Friendly' Abortion Policies?: A Qualitative Exploration Among Religious Counsellors. Sexuality \& Culture. 2019; 23(4), 1230-1249.

20. Hall KS, Sales JM, Komro KA, Santelli J. The state of sex education in the United States. The Journal of Adolescent Health: Official Publication of the Society for Adolescent Medicine. 2016; 58(6), 595.

21. Santelli JS, Kantor LM, Grilo SA, Speizer IS, Lindberg LD, Heitel J, et al. Abstinence-Only-UntilMarriage: An Updated Review of U.S. Policies and Programs and Their Impact. Journal of Adolescent Health. 2017; 61(3), 273-280. 
22. Hessini L. Abortion and Islam: Policies and Practice in the Middle East and North Africa.

Reproductive Health Matters. 2007; 15(29), 75-84.

23. Buse $K$, Hawkes S. Health in the sustainable development goals: ready for a paradigm shift?

Globalization and Health. 2015; 11:13. doi:10.1186/s12992-015-0098-8

24. Green HE. Use of theoretical and conceptual frameworks in qualitative research. Nurse Researcher. $2014 ; 21(6), 34-38$.

\section{Supplementary Files}

This is a list of supplementary files associated with this preprint. Click to download.

- Additionalfile1 InterviewGuide.docx

- Additionalfile2EnglishCONSENTFORM.pdf

- Additionalfile3BanglaCONSENTFORM.pdf 